\title{
O CHAT COMO FERRAMENTA PEDAGÓGICA: EXPERIÊNCIAS A PARTIR DO CURSO DE LETRAS PORTUGUÊS-INGLÊS DO IFCE - CAMPUS BATURITÉ
}

\author{
Carlos Ulisses Moreira TeiXeira Silva ${ }^{1}$, Alanna Oliveira Pereira Carvalho $^{1}$ \\ ${ }^{1}$ Instituto Federal de Educação, Ciência e Tecnologia do Ceará - IFCE \\ <ulissesfts@gmail.com>. <alanna.carvalho@ifce.edu.br>
}

DOI: $10.21439 /$ conexoes.v12i2.1442

\begin{abstract}
Resumo. Com o objetivo de investigar o chat como ferramenta pedagógica na formação inicial do professor, a presente pesquisa apresenta um estudo de caso da utilização do chat pelos discentes da disciplina de TICs aplicadas ao ensino do Curso de Licenciatura em Letras do IFCE - Campus Baturité, no semestre 2017.1. A pesquisa bibliográfica apresentou estudos e pesquisas como os de Xavier (2016), Kenski (2005), Lévy (2000) sobre a utilização das novas tecnologias e sua colaboração numa aprendizagem significativa. Além disso, os dados coletados juntos aos discentes da disciplina por meio de um questionário misto avaliativo da atividade de chat, possibilitou por meio da análise de conteúdo categorias fundamentais na constituição e entendimento do chat como ferramenta pedagógica, foram: a avaliação e autoavaliação da atividade do chat; as potencialidades do chat como ferramenta pedagógica e as dificuldades do chat pedagógico. Os dados analisados permitiram evidenciar que o chat possibilita uma dinamicidade e criatividade na aprendizagem dos discentes por meio da forte interação entre aluno-aluno e aluno-professor. Corroborando para a democratização do ensino, quando evidencia a participação de todos na discussão bem como na construção de ideias e sugestões acerca de determinada temática. No entanto, é necessário que o chat seja planejado e orientado para que os discentes, docente e monitor saibam do papel e função no exercício do ensino por meio da atividade à distância. $\mathrm{O}$ chat então, é potencializador de profundas modificações na estrutura conservadora da sala de aula, proporcionando reflexão sobre e na formação inicial e continuada de professores.
\end{abstract}

Palavras-chaves: Chat. Educação a Distância. Moodle.

\begin{abstract}
In order to investigate the chat as a pedagogical tool in the initial formation of the teacher, this research presents a case study of the use of chat by the discourses of the ICT discipline applied in the teaching of the degree in letters of the IFCE - Campus Baturite, semester 2017.1. The literature search bibliographic search presents studies and researches such as Xavier (2016), Kenski (2005), Lévy (2000) on a use of new technologies and their collaboration in meaningful learning. In addition, the data collected together with discourses of the discipline through a mixed questionnaire evaluated from the chat activity, made possible through content analysis fundamental categories in the constitution and understanding of the chat as a pedagogical tool were: an evaluation and self-assessment of conversational activities; as chat potential as a pedagogical tool and as pedagogical chat difficulties. The data analyzed allowed us to show that the chat allows a dynamicity and creativity in the participants' learning through the strong interaction between student-student and student-teacher. Corroborating for a democratization of teaching, when it shows the participation of all in the discussion as well as in the construction of ideas and suggestions on a certain theme. However, it is necessary to be approached and oriented so that the documents, teacher and monitor know the role and function of any exercise of teaching through distance activity. The chat is then conducive to profound changes in the conservative structure of the classroom, providing reflection on the initial and continuing teacher training.
\end{abstract}

Keywords: Chat. Distance Education. Moodle. 


\section{INTRODUÇÃO}

A Lei no 9.394/1996 de Diretrizes e Bases da Educação Nacional determina que a educação escolar deve vincular-se ao mundo do trabalho e à prática social. Com a promoção das novas tecnologias na vida do cidadão brasileiro, formar indivíduos para dominar esse tipo de conhecimento se tornou importante missão para a escola, visto que a escolarização que não dialoga com a sociedade tende a se tornar insignificante.

Apesar das leis que muitas vezes não se mostram eficazes, em vários aspectos, a preocupação em unir o currículo tradicional com as inovações tecnológicas existe de fato e se torna desafio na realidade atual. No Brasil, o Ministério da Educação, desenvolve inúmeros produtos e cursos que buscam qualificar seus profissionais, dentre eles podemos citar o Guia de Tecnologias Educacionais (MENEZES, 2013), que disponibiliza 134 tipos de tecnologias pré-qualificadas para colaborar com a formação dos professores, e Portais educacionais dos mais variados estilos, como é o caso da RIVED - Rede Interativa Virtual de Educação (<http://rived.mec.gov.br/>) e do Portal do Professor (<http://portaldoprofessor.mec.gov.br/index.html>), que tem por objetivo a produção de conteúdos pedagógicos digitais para docentes ministrarem suas disciplinas.

Sabendo disso, buscamos realizar um estudo que dialogasse diretamente com os anseios dos documentos legais, bem como, os desafios do mundo moderno. Neste artigo encontra-se o recorte da utilização das Tecnologias de Comunicação e Informação - TICs aplicadas ao ensino, especificamente o uso do chat como ferramenta pedagógica na formação inicial do professor. A partir da experiência do pesquisador como monitor da disciplina TICs aplicadas ao ensino do curso de Licenciatura em Letras Português-Inglês do Instituto Federal de Educação Ciência e Tecnologia do Ceará - Campus Baturité, elencou-se as seguintes questões norteadoras deste estudo: quais as contribuições do chat pedagógico na formação inicial do professor? Como a atividade do chat pode ser executada em uma plataforma virtual? Quais são as dificuldades na atividade de um chat pedagógico?

Portanto, o principal objetivo da presente foi de investigar o chat como ferramenta pedagógica na formação inicial do professor. Foram elencados como objetivos específicos: compreender o conceito de chat e sua função pedagógica numa atividade a distância; elencar as dificuldades e potencialidades do uso do chat como ferramenta pedagógica; e analisar o chat como contributo na formação inicial de professores. A pesquisa de abordagem qualitativa e de tipologia exploratória, bibliográfica e estudo de caso (GIL, 2002), possibilitou conhecer e analisar o uso do chat por meio do Ambiente Virtual de Aprendizagem - AVA Moodle em uma turma da disciplina de TICs aplicadas ao ensino no curso de Licenciatura em Letras do IFCE - Campus Baturité.

Espera-se que com esta pesquisa, ao evidenciar um processo de ensino-aprendizagem via chat, desperte nos educadores as potencialidades da utilização das TICs no atual contexto educacional, priorizando por uma formação de aprendizagem significativa e colaborativa na formação de professores. Além disso, fazer com que estes potenciais educadores em formação sejam capazes de refletir seu papel nas mais diferentes plataformas virtuais e na ciberculturd ${ }^{1}$ que eles estão inseridos, incentivando que conheçam essas ferramentas desde antes do momento de assumirem uma sala de aula.

\section{REFERENCIAL TEÓRICO}

\subsection{O chat como ferramenta pedagógica}

O indivíduo, como conhecemos, sempre apresentou a capacidade de reconhecer-se virtualmente, pois afinal de contas o que é a consciência senão a percepção do mundo sobre uma ótica extra-sensorial? Segundo Xavier (2016, p. 32), a linguagem foi o que nos proporcionou a capacidade de interagir com nossos semelhantes, planejando-se intelectualmente e promovendo a troca de saberes. Se nos aprofundarmos nessa concepção, podemos dizer que os seres humanos, ao se comunicarem, desenvolveram o artifício da materialização física do pensamento coletivo. Partindo desse pressuposto, ao analisarmos a história, é possível afirmar que é sob essa circunstância que surge informalmente o processo de ensino-aprendizagem, ressaltando que os conceitos sobre educação só irão se solidificar no período clássico (parte temporal da história da humanidade em que a educação se formaliza por meio da escolarização). Nesse prisma fica claro que acompanhar a virtualização do homem através dos tempos e reavaliar técnicas de ensino-aprendizagem sempre foram assuntos que movimentaram o saber científico.

Hoje, na contemporaneidade, com diversas plataformas virtuais, a espécie humana está descobrindo muito do potencial de sua existência. Pierre Lévy (2000), renomado filósofo que estuda o impacto tecnológico na vida dos indivíduos, afirma que, com a popularização

\footnotetext{
1 "Cibercultura especifica aqui o conjunto de técnicas (materiais e intelectuais), de práticas, de atitudes, de modos de pensamento e de valores que se desenvolvem juntamente com o crescimento do ciberespaço" (LEVI, 1999, p.17).
} 
da internet, o mundo atravessa um processo generalizado de transmutação, ou seja, o homem ao perceber toda sua subjetividade transforma suas relações sociais. Se é assim, as práticas pedagógicas também não estão imunes a essas mudanças. Diante do impacto que o ciberespaç ${ }^{2}$ trouxe para o ambiente educacional, questões como objetivos, finalidade, currículo pedagógico, metodologia estão sendo mais uma vez reavaliadas em essência.

Ao acompanharmos a percepção de Saviani (2005) sobre concepções pedagógicas no Brasil fica perceptível que as pedagogias conservadoras sempre estiveram presente na vida do brasileiro. O que nos leva a crer que, por mais que tenham surgido nas últimas décadas outras concepções mais revolucionárias (destacando nomes como Paulo Freire e Anísio Teixeira), nosso histórico de educação só começa a se preocupar mais efetivamente com a prática social à partir da década de 1980, com as tendências progressistas se popularizando no ambiente escolar. Hoje, na educação tecnológica, o professor ensina o aluno integrar com os mais diversos saberes, e assim, as TICs dentro da sala de aula já estão acontecendo com mais naturalidade.

$\mathrm{O}$ cha ${ }^{3}$ como ferramenta pedagógica surge na efervescência desses novos tempos e pode ser utilizado para auxiliar, maximizar ou até substituir uma aula tradicional. Essa ferramenta inovadora pode ser uma alternativa para dinamizar as dificuldades geradas pela relação espaço-tempo de alunos e professores, como a possibilidade de realizar educação à distância, no entanto, esta modalidade de educação não traz apenas este propósito.

Em uma aula produzida dentro de um Ambiente Virtual de Aprendizagem - $\mathrm{AVA}^{4}$ o ciberespaço se encarrega de estipular novas regras e dilemas para educação do indivíduo. Uma das maiores diferenças é a pluralidade de conteúdo que o aluno tem acesso, devido aos mecanismos de buscas, o discente tem acesso às mais diversas plataformas ao mesmo tempo em que está co-

\footnotetext{
${ }^{2}$ Pierre Lévy (2000, p.92) define o ciberespaço como “[...] espaço de comunicação aberto pela interconexão mundial dos computadores e das memórias dos computadores".

${ }^{3}$ Ferramenta que, segundo Moore e Kearsley (2007, p.354), “duas ou mais pessoas conectadas à internet que conseguem dialogar em tempo real, isto é, conversas síncronas baseadas em texto, ao digitar mensagens no teclado de seus computadores. À medida que a pessoa digita as palavras, elas são mostradas imediatamente aos outros membros do grupo de bate-papo."

4"Os Ambientes virtuais de aprendizagem (AVA) são plataformas que auxiliam na montagem de cursos acessíveis pela internet Eles são elaborados para auxiliar os docentes no gerenciamento de conteúdos para seus alunos, permitem acompanhar constantemente o progresso dos estudantes, e são utilizados como ferramenta para educação a distância e também para complementar aulas presenciais" (MATHIAS; TONET, 2013, p. 2).
}

nectado ao chat uma aula feita a distância, evidenciando todas as mudanças que estão acontecendo no sistema educacional, pois coloca o aluno como protagonista do conhecimento, capaz de buscar inúmeras soluções para apenas uma problemática apresentada pelo professor, e assim desenvolver um pensamento crítico para optar pela resposta que melhor se adapte ao seu ponto de vista e a própria aplicabilidade do conteúdo para aquele problema posto em questão.

\begin{abstract}
A aprendizagem colaborativa destaca a participação ativa e a interação, tanto dos alunos como dos professores. O conhecimento é visto como um constructo social e, por isso, o processo educativo é favorecido pela participação social em ambientes que propiciem a interação, a colaboração e a avaliação [...] (AMARAL; ROSINI, 2008, p. 146).
\end{abstract}

Sabendo disso, quando se afirma que a aprendizagem pode ser colaborativa, o chat realmente se tornar pedagógico. Na evolução da virtualização dos seres pensantes, a necessidade é fazer com que o aluno saiba investigar e aceite que na contemporaneidade não existem verdades absolutas. Nesta significação, a proposta de chat pedagógico pode se tornar mais interessante do que uma conversa presencial. Visto que a consciência do aluno passa por um upgrade ao se conectar na internet e não se sente pressionado pela oralidade formalizada do contexto acadêmico a ser utilizada ou pelas sensações de insegura ao lidar pessoalmente com os outros ou um público de sala de aula.

No Brasil, assim como em todo mundo, a democratização da internet ainda está em processo. Segundo Xavier (2016), uma pesquisa realizada pela União Internacional de Tecnologia - UTI averiguou-se que os usuários da rede estão crescendo exponencialmente, muitos devido ao uso dos smartphones. Sendo assim, para se pensar em TICs aplicadas ao ensino é necessário avaliar o que é fundamental para o manejo do internauta e as dificuldades recorrentes do corpo discente ao mesmo tempo em que se elaboram estratégias para ministrar o conteúdo curricular da matéria proposta.

Não é fácil dominar toda essa complexidade. Para uma prática docente crítica e construtivista, Luckesi (2011) nos leva a crer que avaliar a prática docente, sejam apresentando resultados positivos ou negativos, é a maneira mais eficaz para evidenciar toda as questões que perpassam o processo de aprendizagem. Dessa maneira é possível que as atividades propostas sejam reavaliadas na prática do ensino. 


\section{PROCEDIMENTOS METODOLÓGICOS}

A presente pesquisa situa-se em uma abordagem qualitativa, pois busca investigar como uma experiência com chat pedagógico pode contribuir para a formação de futuros professores. Gil (2002) afirma que a pesquisa do tipo exploratória projeta ao pesquisador maior contato e aproximação com o problema ou objeto de estudo, tornando-o compreensível. Sendo assim, o estudo de caso e a pesquisa bibliográfica buscam construir hipóteses a respeito de como a aprendizagem no ambiente virtual deve acontecer e se ela é capaz de reverberar na formação inicial de novos professores.

Muito se fala sobre as mudanças revolucionárias que a internet é capaz de produz na prática pedagógica, mas para que elas aconteçam de fato é necessária a formação do corpo docente e condições físicas para sua estruturação nas instituições de ensino. No Instituto Federal de Educação Ciência e Tecnologia do Ceará - IFCE campus Baturité, lócus dessa pesquisa, no curso de Licenciatura em Letras - Português e Inglês, os discentes têm a oportunidade de cursarem a disciplina de TICs aplicadas ao ensino, no segundo semestre de curso, que visa potencializar a mediação pedagógica com as novas tecnologias no ensino de Língua Portuguesa e Inglesa.

Esta pesquisa se deu junto a turma do semestre 2017.1, cuja disciplina recebeu o apoio de monitoria do presente pesquisador, bem como possibilitou a vivência do chat no Moodle - AVA pautado por uma filosofia sócio construtivista ${ }^{5}$ utilizada pelo IFCE. Através do chat, uma atividade constitutiva da disciplina, decidimos investigá-la a partir da integração, colaboração e respostas dos alunos participantes, tanto durante o chat como em uma avaliação a posteriori. Para isso foi necessário elaborar um plano de aula, reconhecer a plataforma que seria utilizada para a atividade e avaliar todo o processo por meio da participação no chat, bem como na elaboração de um questionário na própria plataforma para os alunos respondessem mediante a sua participação.

Para experimentar essa vivência foi necessário investigar a possibilidade de trabalhar dentro da plataforma Moodle, estabelecendo contato com a equipe de Educação a Distância do Instituto para a criação de uma conta para cada participante da disciplina. É de conhecimento daqueles que estão inseridos no ciberespaço que cada plataforma passa por um processo gradativo de acomodação. Alguns alunos aprenderam com maior facilidade a interagir com essas informações, outros não.

\footnotetext{
${ }^{5}$ Abordagem educacional com foco na interação, evidenciada nos estudos de Lev Vygotsky no século XX entendendo o homem e seu desenvolvimento numa perspectiva sociocultural.
}

Pensando nisso, para que a aula alcançasse um resultado positivo para todos, foi aconselhado que o monitor da turma também participasse do chat para instruir e tirar as dúvidas dos alunos.

Para que um chat pedagógico possa fluir é importante que exista algum assunto em comum para ser debatido. Sendo assim, a plataforma Moodle oferece a seguinte recurso: pode-se disponibilizar algum material - como um artigo para que todos leiam e em seguida entrar no chat para discuti-lo. O artigo Das Salas de Aula aos Ambientes Virtuais de Aprendizagem (KENSKI, 2005) foi disponibilizado com antecedência para que os alunos da disciplina pudessem tomar parte.

Como o objetivo era do discente interagir em um chat que tem por característica a interatividade virtual, a atividade foi realizada à distância, em um sábado letivo, proporcionando maior conforto àqueles que possuem internet em sua residência ou tem acesso a ela na casa de parentes ou colegas. As perguntas de discussão foram elaboradas pelos discentes, que formaram grupos em aula anterior para dividirem os tópicos do texto e elaborarem uma pergunta sobre cada tópico. A intenção foi de considerá-los mediadores para nortearem as discussões e o nível de debate, que deveria perpassar pelas fronteiras do artigo estudado. Depois de terminada a atividade no chat, foi pedido para que os alunos realizassem uma avaliação da atividade, colocando os pontos positivos e negativos observados. O mesmo questionário (APÊNDICE A) foi disponibilizado no tópico referente ao chat, facilitando o acesso na plataforma logo após a finalização deste.

A análise de conteúdo, conforme Bardin (2009), dos questionários de avaliação possibilitaram a esta pesquisa analisar algumas categorias que emergiram, tais como: a avaliação e autoavaliação da atividade do chat; as potencialidades do chat como ferramenta pedagógica e as dificuldades do chat pedagógico.

Nesse sentido, o caminhar procedimental até a consolidação dos questionários avaliativos do chat possibilitam enfatizar e embasar algumas afirmações e achados que serão detalhados no próximo tópico.

\section{RESULTADOS E DISCUSSÕES}

A partir da análise de conteúdo proporcionada pelas respostas do questionário avaliativo da atividade do chat (APÊNDICE A), foi possível elencar algumas categorias que serão detalhadas neste tópico. É importante ressaltar a o questionário propiciou não apenas a avaliação da atividade pelo discente, mas a autoavaliação da sua participação e contribuições qualitativas acerca da atividade em si. 
Serão desenvolvidas as seguintes categorias de análises: a avaliação e autoavaliação da atividade do chat; as potencialidades do chat como ferramenta pedagógica e as dificuldades do chat pedagógico.

\subsection{A Avaliação e a Autoavaliação da Atividade do chat}

O instrumento avaliativo do chat foi disponibilizado aos discentes na própria plataforma Moodle, e de forma interativa, foram evidenciadas questões abertas e fechadas. Dentre elas, as questões fechadas que se manifestaram nesta categoria foram: a participação no chat, a avaliação pessoal - participação e atuação, do professor da disciplina e do tutor - monitor, numa escala de ótimo a ruim. Quanto às questões abertas apenas uma foi considerada nesta categoria: "As perguntas trazidas pelos grupos incentivaram a discussão e aprendizagem?"

Desse modo, buscou-se por meio de uma análise da frequência dos conceitos da escala avaliativa, bem como do conteúdo da questão aberta, relacionar os achados ao embasamento já discutido anteriormente, e de outros autores e pesquisas que evidenciam esta temática.

A ferramenta do questionário na plataforma Moodle, possibilita uma pré-análise quanto aos dados quantitativos por meio de gráficos e porcentagens dos respondentes. Já as questões abertas há somente o agrupamento de todas as respostas registradas. Nesse sentido, os gráficos abaixo são produtos da própria plataforma, o que compreende ao professor que a utiliza maior dinamicidade na sistematização de uma atividade como esta.

Participaram do questionário avaliativo 17 alunos, do total de 28 matriculados na disciplinas, ou seja, $60 \%$ da turma, mais da metade dos alunos responderam ao questionário. Dentre as justificativas de falta na atividade encontram-se: incompatibilidade de horário com o trabalho, falta de planejamento com outras demandas pessoais ou familiares e alguma dificuldade de acesso a internet ou cadastro na plataforma.

Sendo esta atividade realizada no contraturno do horário da disciplina e em dia de final de semana, conferese como natural a ausência de alguns alunos. No entanto, quanto a problemas relacionados a internet ou mesmo ao acesso a plataforma vê-se que muitos ainda têm dificuldade de perceberem a integração entre o ambiente presencial e a distância, se fixando no primeiro e não orientando-se nas aulas sobre as regras e intruções para acesso ao segundo.

Com relação a participação no questionário, 15 $(88,24 \%)$ dos $17(100 \%)$ alunos participaram ativa- mente da atividade, sendo 2 os faltosos $(11,76 \%)$, um por dificuldades de acesso a plataforma e outro sem evidenciá-la. A dificuldade no acesso pode ter sido também em virtude da pouca experimentação na plataforma mediante as atividades anteriores, o que conota maior apreço pelas atividades presenciais do que àquelas a distância. Considera-se que isto se dê em virtude do curso ser presencial, e das demais disciplinas não terem qualquer contato com atividades e recursos em TICs que potencializam esse contato ao discente. Apesar disso, Ponte (2000, p.15) percebe a importância dos professores para o processo de democratização das TICs no ensino:
Não deixa de ser curioso assinalar que são os professo- res mais empenhados pedagogicamente -ou seja, aque- les que procuram usar métodos inovadores para suscitar a aprendizagem dos alunos- os que mais usam a inter- net nas suas salas de aula . Pelo menos até determinado nível, parece não haver incompatibilidade entre interesse pela inovação educacional e pela inovação tecnológica por parte do professor.

Portanto, a profissão docente assinala a importância de compreender essas novas tecnologias desde a formação inicial, visto que é na prática profissional, em sala de aula, que o professor percebe melhor o uso e potencialidades dessas tecnologias.

A participação dos discentes na atividade de chat foi ponderada na escala de ótima a ruim. No gráfico acima (FIGURA 2), percebe-se que os discentes se avaliaram com boa ou ótima participação, sendo $70 \%$ do total, ou seja, seis discentes em cada um destes conceitos. Já nos outros dois conceitos regular e ruim notam-se dois discentes, evidenciando 5\% do total, respectivamente.

Estudos como o de Silva, Bartholomeu, Claus (2007), trazem referências de que a autoavaliação auxilia no processo de ensino e de aprendizagem, projeta nos alunos a coresponsabilidade que eles têm no que aprendem numa instituição de ensino.

\footnotetext{
A auto-avaliação é um processo pelo qual um indivíduo, além de avaliar uma produção, uma ação, ou uma conduta da qual ele é o autor, também avalia suas capacidades, seus gostos, seu desempenho, suas competências e habilidades. É um processo cognitivo complexo, pelo qual um indivíduo (aprendiz ou professor) faz um julgamento, com o objetivo de um melhor conhecimento pessoal, visando ao aperfeiçoamento de suas ações e ao seu desenvolvimento cognitivo (SILVA; BARTHOLOMEU; CLAUS, 2007, p. 92).
}

Desse modo, percebe-se que atividades que permitem uma autoavaliação, e a sistematização da mesma por parte do professor para entender seus resultados e agir diante disso, proporcionam uma reflexão da práxis em consonância com as demandas e especificidades 


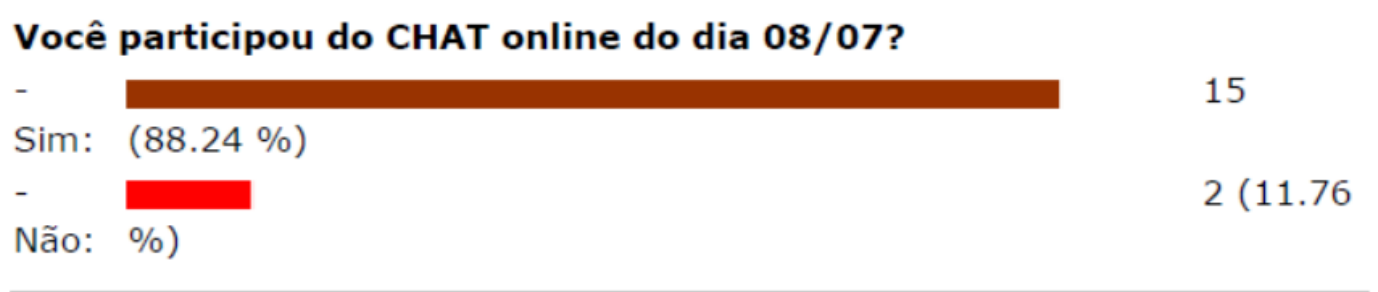

Figura 1: Participação dos discentes na atividade do chat da disciplina TICs aplicadas ao Ensino 2017.1 Fonte: Moodle (IFCE, 2017).

\section{Como você avalia a sua participação no CHAT?}

- Ótima:

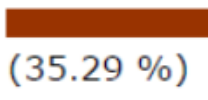

- Boa:

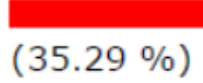

-

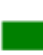

Regular: $(5.88 \%)$

- Ruim:

$$
(5.88 \%)
$$

Figura 2: Avaliação da participação dos discentes na atividade do chat da disciplina TICs aplicadas ao Ensino 2017.1 Fonte: Moodle (IFCE, 2017).

de aprendizagem dos discentes. Nesse sentido, deve-se buscar mais do que o conceito avaliado como o fora no questionário, mas no detalhamento deste por meio de uma justificativa.

Com relação a avaliação do professor e monitor da disciplina, como mostra a imagem acima, nota-se que em mais da metade, os discentes, compreendem como participações ótimas e boas, tanto do professor - $64,71 \%$ e $17,65 \%$, quanto do monitor/tutor - 47,06\% e $29,41 \%$, respectivamente. Já nos conceitos regular e ruim quanto ao professor são nulos, e quanto ao monitor apenas $5,88 \%$ confere como regular, ou seja, apenas um discente.

A avaliação destes atores permite regulação no processo de ensino, seja nas orientações ou determinações dos diferentes papéis que professor e monitor exercem em uma atividade disciplinar. Na educação a distância é preciso deixar claro os papéis a serem desempenhados por cada ator, para que o seu desenvolvimento aconteça de forma satisfatória com os objetivos estabelecidos. A boa avaliação acima, sustenta a boa relação professoraluno no exercício do ensino, especificamente da atividade de chat.

\begin{abstract}
A relação professor-aluno pode ser profundamente alterada pelo uso das tecnologias. Na resolução de um problema, na realização de um projeto, na coleta e análise de dados sobre um determinado assunto, o professor realiza um mergulho junto com os alunos para poder responder às suas dúvidas e questões. A proximidade com os alunos ajuda-o a compreender suas idéias, olhar o conhecimento sob novas perspectivas e também aprender (KENSKI, 2005, p. 79).
\end{abstract}

Nesse sentido, as relações afetivas que envolvem o processo de ensino e de aprendizagem aparentam ser impossíveis na educação a distância, no entanto, se tornam até mais facilitadas quando o discente se vê necessário a comentar, responder, exemplificar, e o professor a dar esta abertura ao aluno constituindo um movimento mais interacional no cotidiano escolar.

Com relação a avaliação dos alunos às questões discutidas no chat, referentes ao texto Das Salas de Aula aos Ambientes Virtuais de Aprendizagem (KENSKI, 2005), percebe-se que a grande maioria dos discentes confirmaram que as perguntas trazidas incentivaram a discussão e aprendizagem.

Da frequência analisada, dos 15 participantes, apenas 1 deles ponderou negativamente a importância das questões, isso por conta de problemas técnicos relacio- 


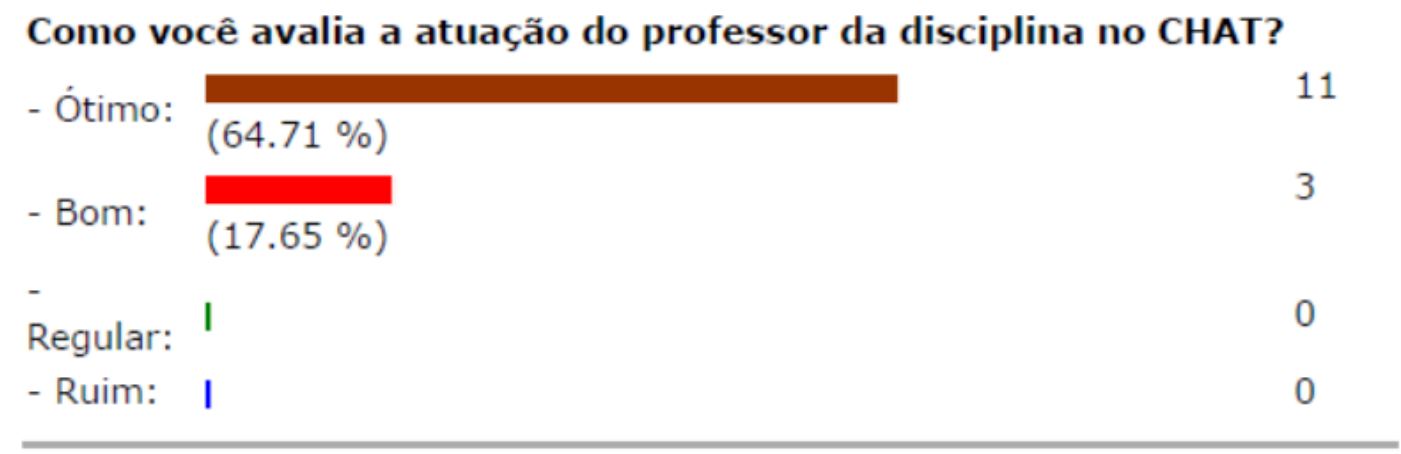

\section{Como você avalia a atuação do tutor da disciplina no CHAT?}

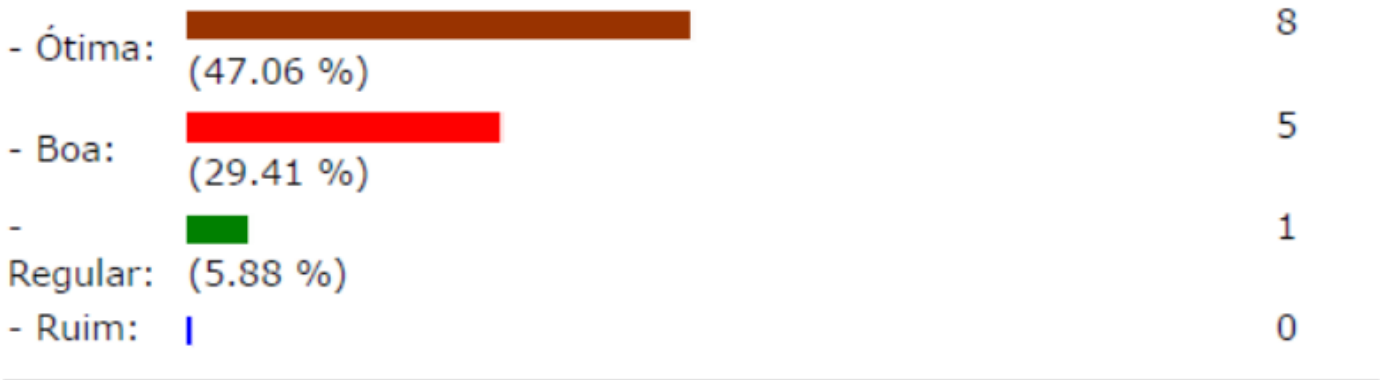

Figura 3: Avaliação do professor e monitor/tutor na atividade de chat da disciplina TICs aplicadas ao Ensino 2017.1 Fonte: Moodle (IFCE, 2017).

nados a conexão de internet que possibilitou pouca participação do mesmo. Os demais discentes ainda avaliaram que a discussão possibilitou além da integração da turma, maior destaque ao papel das TICs no ensino, bem como ao papel do docente diante delas.

Isso corrobora tanto para o assunto do texto em questão trabalho da Kenski (2005), quanto da projeção das questões elaboradas pelos grupos. Proporcionando por meio de uma linguagem clara e objetiva, elementos para reflexão e crítica a partir do estudo do texto realizado.

Nesta categoria percebe-se que o mecanismo de autoavaliação, bem como, da avaliação dos atores e da metodologia da atividade realizada confere à ferramenta utilizada - chat, um conceito de satisfatoriedade na visão dos discentes participantes e respondentes do questionário analisado. Percebe-se que na avaliação realizada, os discentes refletem e criticam tanto o conteúdo quanto elementos que favorecem sua própria aprendizagem (LUCKESI, 2011).

\subsection{Dificuldades na Atividade do chat}

A categoria anterior demonstra que além de acertos na atividade existiram erros ou mesmo dificuldades téc- nicas que interferiram na visão desta atividade como potencializadora da aprendizagem.

A maioria dos participantes evidenciaram a conexão com a internet, ou erro na própria página da plataforma e até mesmo a interface do chat dificultaram o acesso, a leitura das mensagens e fluidez nas respostas quando digitadas.

O chat é uma estratégia cujos limites se materializam nos recursos operacionais, desde a velocidade da internet utilizada ao processamento do sistema operacional do computador operado pelo sujeito, bem como, nos recursos humanos como a disponibilidade e correspondência entre tutor e aluno (BRITO, 2003). Outro fator limitante seria o número de participantes. Em grupos numerosos, o chat pode tornar-se improdutivo e desmotivante, pois é difícil acompanhar o ritmo e a conexão de todas as postagem.

Nesse sentido, nota-se que o quantitativo de discentes foi proporcional ao acompanhamento realizado, ou seja, havia quinze discentes para professor e monitor atentarem e acompanharem. O que é evidenciado por meio da avaliação positiva com relação a interação deles mesmos por meio do chat, apesar de um dos discentes evidenciar que a participação da turma poderia 
ter sido melhor visto o número de alunos da turma e os participantes no chat.

\subsection{Potencialidades da Atividade do chat}

As potencialidades da atividade do chat foram analisadas a partir de duas questões: pontos positivos dessa atividade e sugestões de outras atividades. Nesse sentido, foi-se desenvolvida a análise das respostas de acordo com a semelhança e congruência dos conceitos e percepções que trouxeram, sistematizados na Figura 4.

\section{Kenski (2005, p.6) nos aponta que \\ esses espaços virtuais de aprendizagem oferecem condi- ções para a interação (síncrona e assíncrona) permanente entre os seus usuários. A hipertextualidade facilita a pro- pagação de atitudes de cooperação entre os seus parti- cipantes, para fins de aprendizagem. A conectividade garante o acesso rápido à informação e à comunicação interpessoal, em qualquer tempo e lugar, sustentando o desenvolvimento de projetos em colaboração e a coorde- nação das atividades.}

Isso mostra que o trabalho se torna mais dinâmico, interativo e democrático, pois é para se funcionar de forma colaborativa. Outro fator interessante é a comodidade como aponta Almeida (2003, p.5) que "as atividades se desenvolvem no tempo, ritmo de trabalho e espaço em que cada participante se localiza, de acordo com uma intencionalidade explícita e um planejamento prévio denominado design educacional, o qual constitui a espinha dorsal das atividades a realizar, sendo revisto e reelaborado continuamente no andamento da atividade".

Além disso, pode-se perceber que as sugestões dos discentes geram alguma possibilidade de melhorar tanto as atividades com TICs como promover uma visão mais ampla desse processo no âmbito educacional. Das sugestões afirmadas pelos discentes estão: utilização de jogos educativos; adoção dessa atividade na metodologia docente de outras disciplinas; pesquisas e pequenos resumos discentes sobre elas; utilização de outros aplicativos para discussão e compartilhamento de informações - imagens, vídeos, áudios e textos, como o Whatsapp; e por fim, discussões temáticas.

Nesse sentido, podemos perceber que quanto à metodologia de ensino e de aprendizagem os discentes sugeriram não somente outras TICs como os jogos, aplicativos de compartilhamento de dados, bem como, atividades de resumo e discussões. Ou seja, tanto metodologias que envolvem novas tecnologias ou não, mas essencialmente que se alimentam desta perspectiva sociointeracionista. Pois vê-se que a buca de outras atividades como sugestões contemplam a interação como parte essencial, exceto as pesquisas que envolvem um caráter mais individual.

Dessa forma, podemos conceber as TICs por uma perspectiva sociointeracionista, Vygotsky (2008) apud Maggi e Américo (2013, p. 12) nos faz perceber que “[...] a aprendizagem é mais do que a aquisição de capacidades para pensar, é a aquisição de muitas capacidades para pensar sobre várias coisas".

Nesse sentido, baseado nessa perspectiva, a aprendizagem do indivíduo ocorre quando imerso em sua sociedade e cultura, e mais que isso quando da sua interação com os agentes e participantes dessa cultura. Desse modo, a aprendizagem precisa ser mediada e consolidada por meio de instrumentos e atores que permitam essa interação e mediação do meio - indivíduo. Então,

as TICs podem servir como importantes instrumentos mediadores e fomentadores da aprendizagem. Esses mediadores são instrumentos que transformam a realidade em vez de imitá-la; sua função não é se adaptar passivamente às condições do meio, mas, sim, modificá-las ativamente (MAGGI; AMÉRICO, 2013, p. 12).

A base de uma aprendizagem sociointeracionista perpassa não somente pela mediação de agentes ou instrumentos, como as TICs, mas pelo planejamento e organização do próprio processo de intervenção. Para realizar a democratização na participação dos alunos e a dinamicidade na atividade de ensino-aprendizagem como o chat, o planejamento é passo fundamental. É por meio dele que a concepção do professor e da educação que estabelece se fazem presentes, e além disso, sua intervenção é de fato organizada e sistematizada.

\section{CONSIDERAÇÕES FINAIS}

Por meio de um estudo de caso, com abordagem qualitativa e procedimentos exploratórios de pesquisa bibliográfica, investigou-se o chat como ferramenta pedagógica na formação inicial do professor. Para isso, foi preciso conhecer o conceito de chat, elencar as dificuldades e potencialidades desta ferramenta, bem como analisá-la, permitindo que a autoavaliação discente fosse constituinte desse processo.

O papel da avaliação de uma metodologia utilizada em sala de aula é essencial para se perceber os (des)caminhos da aprendizagem ali assumidos e motivados. Os achados do estudo permitiram perceber que o chat quando planejado e orientado permite interação e aprendizagem dos discentes. Além disso, contribui 


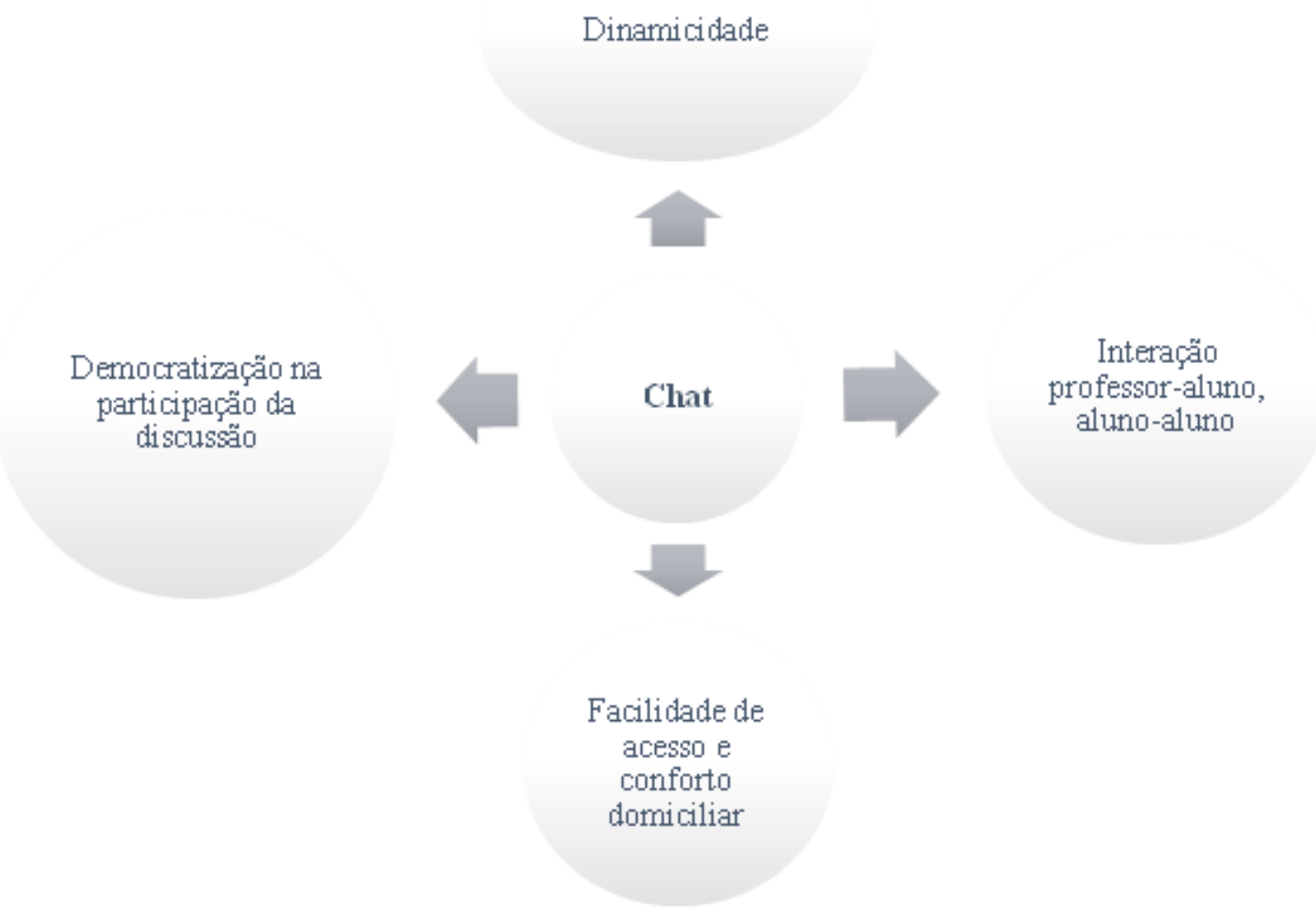

Figura 4: Pontos positivos na atividade de chat da disciplina TICs aplicadas ao Ensino 2017.1

Fonte: Elaborada pelos autores.

no processo de ensino quando revela uma configuração mais simples na relação aluno-aluno e aluno-professor.

Percebe-se que o exercício do chat pedagógico em sala de aula virtual faz com que os educadores assumam práticas construtivistas, se distanciando de tendências conservadoras. Quando trabalhamos esse tipo de atividade na formação inicial do professor, ao ter acesso a outras metodologias e artifícios, o educador passa por um processo de transformação.

Ao analisarmos todos os resultados que esse estudo de caso nos proporciona, podemos perceber que trabalhar com TICs aplicadas ao ensino ainda é um desafio. Assim como Paulo Freire (1991) costumava sempre evidenciar que ninguém nasce para ser professor, se forma na prática e na permanentemente reflexão sobre ela, para um educador dominar o uso de tecnologias dentro da sala de aula, precisa estar sempre a experimentar atividades com seus alunos e analisar os resultados encontrados.

Para que esse tipo de aprendizagem ganhe cada vez mais espaço nas redes de ensino, a formação do corpo docente é de fundamental importância. Uma instituição de ensino que apresenta professores que não conseguem se relacionar com a sociedade imersa no uso das tecnologias, aos meios de comunicação e que não seja capaz de buscar propostas interativas para a nova geração de alunos mais tecnológicos, acaba por ministrar aulas arcaica e longe da realidade. Eis uma proposta criativa a partir desta pesquisa: como os docentes do IFCE utilizam o Moodle em suas disciplinas de cursos voltados para a formação de professores?

Ademais, o percurso da pesquisa é sempre oportuno na resposta à dúvida, bem como a curiosidade, seja para solucionar problemas ou ajudar na sua resolução. É nesse caminho que aqueles interessados e formados para a docência não devem deixar de trilhar.

\section{REFERÊNCIAS}

ALMEIDA, M. E. B. d. Educação a distância na internet: abordagens e contribuições dos ambientes digitais de aprendizagem. Educação e pesquisa, SciELO Brasil, v. 29, n. 2, p. 327-340, 2003. 


\begin{abstract}
AMARAL, R. d. C. B. d. M.; ROSINI, A. M. et al. Concepções de interatividade e tecnologia no processo de tutoria em programas de educação a distância: novos paradigmas na construção do conhecimento. Revista Intersaberes, v. 3, n. 6, p. 141-154, 2008. Disponível em: <https://uninter.com/intersaberes/ index.php/revista/article/viewFile/134/107> Acesso em: 31 out 2017.
\end{abstract}

BARDIN, L. Análise de Conteúdo. 1. ed. Lisboa: Edições 70, 2009.

BRITO, M. S. S. Tecnologias para a ead via internet. In: ALVES, L. R. G.; NOVOA, C. C. (Ed.). Educação e tecnologia: trilhando caminhos. Salvador: Editora da Uneb, 2003. v. 1, p. 62-87. Disponível em: <http: //softwarelivrenaeducacao.wordpress.com/2009/10/20/ leitura-online-educacao-e-tecnologia-trilhando-caminho >. Acesso em: 31 out 2017.

FREIRE, P. A educação na cidade. 1. ed. São Paulo: Cortez, 1991.

GIL, A. C. Como elaborar projetos de pesquisa. 1. ed. São Paulo: Atlas, 2002.

KENSKI, V. M. Das salas de aula aos ambientes virtuais de aprendizagem. In: Anais do $\mathbf{1 2}^{\mathbf{0}}$ Congresso Internacional de Educação a Distância. Florianópolis: $12^{\circ}$ Congresso Internacional de Educação a Distância, 2005. Disponível em: <http://www.abed.org.br/congresso2005/por/pdf/ 030tcc5.pdf> Acesso em: 09 out 2017.

LÉVY, P. Cibercultura. 1. ed. São Paulo: Editora 34, 2000.

LUCKESI, C. C. Avaliação da aprendizagem escolar: estudos e proposições. 1. ed. São Paulo: Cortez, 2011.

MAGGI, N. R.; AMÉRICO, R. M. Linguagem, aprendizagem e tecnologias da informação: uma leitura no âmago do sociointeracionismo segundo vygotsky. Nonada: letras em revista, Laureate International Universities, v. 2, n. 21, p. 1-14, 2013. Disponível em: <http: //www.redalyc.org/pdf/5124/512451671018.pdf> Acesso em: 03 nov 2017.

MENEZES, P. B. Guia de tecnologias educacionais da educação integral e integrada e da articulação da escola com seu território 2013. Brasília, 2013. P. 55. Disponível em: <http://portal.mec.gov.br/index. php?option=com_docman\&view=download\&alias= 14545-guia-tecnologias-20130923-pdf\&category_ slug=novembro-2013-pdf\&Itemid=30192> . Acesso em: 30 out 2017.

MOORE, M. G.; KEARSLEY, G. Educação a distância: uma visão integrada. 1. ed. São Paulo: Cengage Learning, 2008.

PONTE, J. P. d. Tecnologias de informação e comunicação na formação de professores: que desafios? Revista Iberoamericana de educación, v. 1, n. 24, p. 63-90, 2000.

SAVIANI, D. Escola e Democracia. 1. ed. Campinas: Autores Associados, 2005.

SILVA, K. A. d.; BARTHOLOMEU, M. A. N.; CLAUS, M. M. K. Auto-avaliação: uma alternativa contemporânea do processo avaliativo. Revista Brasileira de Linguística Aplicada, SciELO Brasil, v. 7, n. 1, p. 89-115, 2007. Disponível em: <http://www.scielo.br/pdf/rbla/v7n1/06.pdf > Acesso em: 31 out 2017.

XAVIER, A. C. A retórica digital das redes sociais. In: XAVIER, A. C.; LEVY, P. (Ed.). Hipertexto e cibercultura: links com literatura, publicidade, plágio e redes sociais. São Paulo: Respel, 2016. p. 27-60. 